\title{
Experimental Study of Space Charge Characteristics in Thin Films of Polyvinyl Chloride Nanocomposites
}

\author{
Ahmed Thabet \\ Faculty of Energy Engineering, \\ Nano-Technology Research Centre, Aswan University, Aswan, EGYPT
}

\begin{abstract}
This paper aims to provide a view of a lively space charge accumulation in new polyvinyl chloride (PVC) nanocomposite thin films. Space charges in thin films of polyvinyl chloride nanocomposite insulation materials are done to distort the local electric fields and affect high-field conduction and breakdown phenomena, whatever, adding nanofillers to polyvinyl chloride changes their electrical ages. Thus, space charge characteristics have been investigated by pulsed electroacoustic (PEA) measurement system for thin thickness of polyvinyl chloride nanocomposite materials which filled with different separately nanoparticles like $\mathrm{ZnO}, \mathrm{TiO}_{2}$, and $\mathrm{Al}_{2} \mathrm{O}_{3}$. This paper depicts that space charge accumulation in polyvinyl chloride nanocomposites differs with respect to type and concentration of nanoparticles.
\end{abstract}

Keywords: Space charge, Nanocomposite, PEA system, Polymers, Polyvinyl Chloride, Insulation, Nanoparticles

\section{Introduction}

Space charge accumulation is known to play a very important role in the aging and breakdown of HVDC solid polymeric insulation, due to local electric field enhancement. If the applied field exceeds the threshold for space charge accumulation, charge injected from the electrodes can accumulate in traps located at the interface with electrodes and in the insulation bulk [1-5].The existence of such a threshold would have considerable impact on the design of insulation systems. Designing an insulation system for an electrical stress below the threshold would assure very long life and high reliability, provided that there are no other significant stresses acting on the insulation. In order to obtain a better understanding of the role of the nanoparticles in the process of dielectric breakdown, lifetime, and space charge behavior, the interfacial region needs to be investigated $[6,7]$. A number of mechanisms have been inferred for the electro thermal aging process occurring in insulating polymers with the aim of deriving usable life expressions. These mechanisms have followed two prevailing directions: a macroscopic approach, based on an overall description of degradation processes, and a microscopic approach, based on the presumption that the prevailing cause of electrical and mechanical aging in practical insulation systems is accelerated localized degradation triggered by micro defects $[8,9]$. For the enhancement of electrical insulation reliability and compact design in electric power apparatus, the electrical properties of polymer composites filled with metal oxide particles will play an important role. Recently, it has been recognized that the introduction of metal oxide nanoparticles to polymer has unique dielectric behavior and advantages when compared to the base polymer and the polymer filled with conventional micrometric particles [10-16]. The effects of nanosized particle additives on the electrical properties of common dielectrics are currently of considerable interest [17-22]. The trapped space charge density is obtained from the depolarization current characteristics according to the following expression [23],

$$
q(t)=\int_{0}^{t} i(t) d t
$$

Where, $\mathrm{i}(\mathrm{t})$ is the depolarization current, $\mathrm{q}(\mathrm{t})$ the trapped charge density and $\mathrm{t}$ is time. 
Polyvinyl Chloride is stronger and more rigid than other general purpose thermoplastic materials like ac and dc cable insulations, etc. It has a high tensile strength and modulus of elasticity. Nowadays, the research goes towards for concerning about the effect of nanotechnology on space charge distribution in polymeric insulations. With a continual progress in polymer nanocomposites, the current research depicts the effects of types and concentration of nanoparticles in new nanocomposite industrial polymer material. Space Charge Dynamics in polyvinyl chloride Nano-composite materials which use $\mathrm{ZnO}$ or $\mathrm{TiO}_{2}$ or $\mathrm{Al}_{2} \mathrm{O}_{3}$, nanoparticles separately under DC Stress have been investigated and discussed experimentally.

\section{Experimental Setup}

Acoustic wave propagation in the thick samples is significantly attenuated and dispersed due to the loss and dispersive properties of the polymer and principle of space charge measurement using the PEA technique. The specifications of each module in PEA system is being as follows: The oscilloscope (LECROY, LC334AM, 500MHz), impulse generator (TECHMP, 10nsec), VHF fixed attenuator $(30 \mathrm{~W}, 40 \mathrm{~dB})$ and stabilized voltage supply (Type L30). Measurements are performed in silicon oil to avoid partial discharges, and to keep the temperature constant. The applied voltage was monitored simultaneously by using a resistance voltage divider. In order to observe the effect of pre-stressing on impulse breakdown, it existed that an impulse generator, and a coupling capacitor (2000 pF). Figure 1 shows Life photo and Schematic diagram of the PEA system which used in measuring.

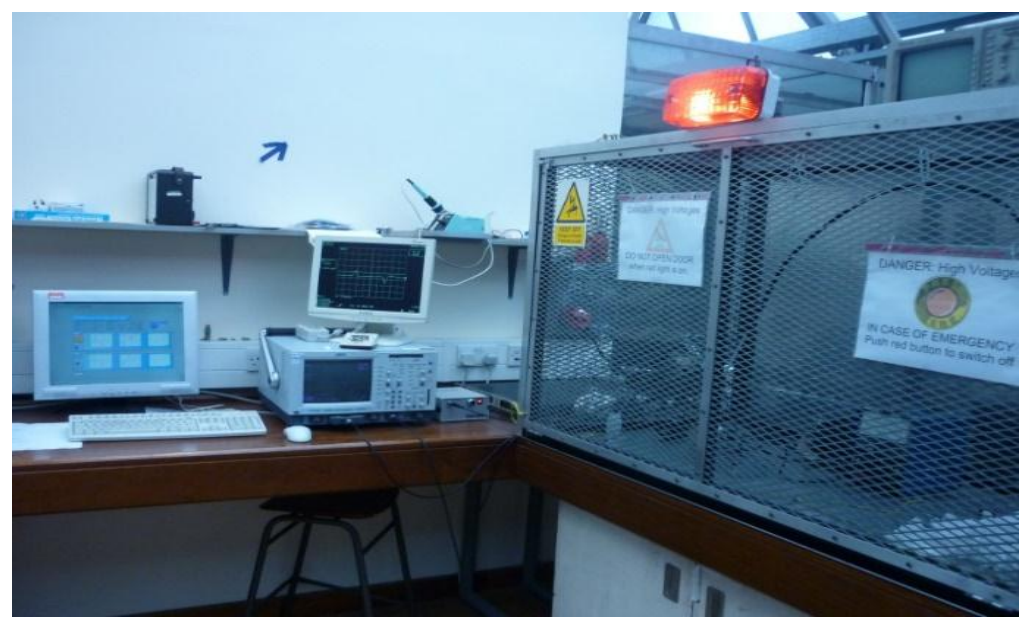

(a) Life photo

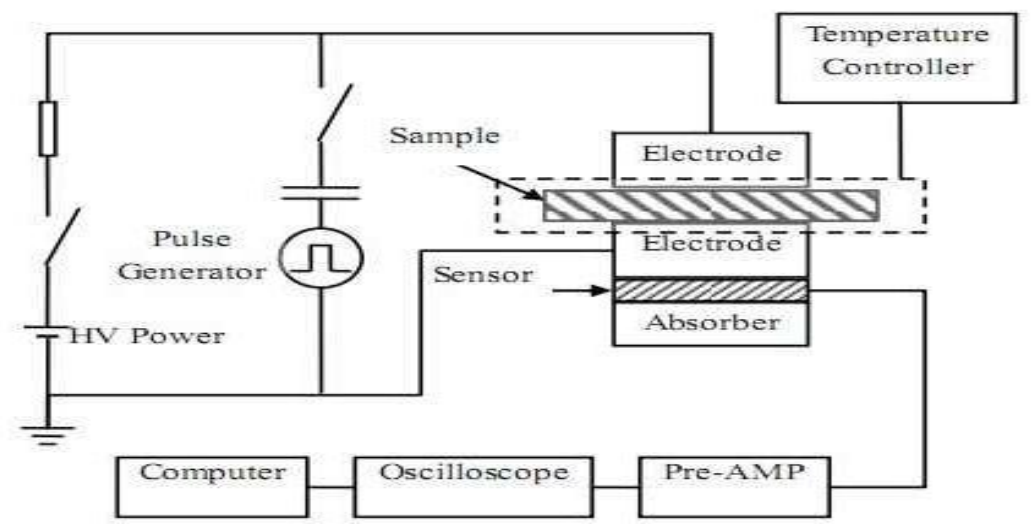

(b) Schematic diagram

Figure 1. PEA system testing equipment's 


\section{Material Preparation and Characterization}

Although nanoparticles are generally considered a discovery of modern science, they actually have a very long history. With respect to electrical and mechanical importance of zinc oxide, titanium dioxide, and aluminum oxide in industrial applications, they are suggested to embed as inclusions in Polyvinyl Chloride. Additives of clay, zinc oxide, and fumed silica nanoparticles to the base industrial polymers (Polyvinyl Chloride) has been fabricated by using mixing, ultrasonic, and heating processes in nanotechnology Research Centre, Aswan - Egypt. Preparations of studied polyvinyl chloride nanocomposites have been used SOL-GEL method. The sol-gel processing of the nanoparticles inside the polymer dissolved in non-aqueous or aqueous solution is the ideal procedure for the formation of interpenetrating networks between inorganic and organic moieties at the milder temperature in improving good compatibility and building strong interfacial interaction between two phases. This process has been used successfully to prepare nanocomposites with nanoparticles in a range of polymer matrices. Several strategies for the sol-gel process are applied for formation of the hybrid materials. One method involves the polymerization of organic functional groups from a preformed sol-gel network. The sol- gel process is a rich chemistry which has been reviewed elsewhere on the processing of materials from glass to polymers. The organic-inorganic hybrid nanocomposites comprising of polymer, and nanoparticles were synthesized through sol-gel technique at ambient temperature. The inorganic phase was generated in situ by hydrolysis-condensation of tetraethoxysilane (TEOS) in different concentrations, under acid catalysis, in presence of the organic phase, polymer, dissolved in formic acid [24]. Penetration of nanofillers into polyvinyl chloride has been shown by SEM measurements in Figure 2.

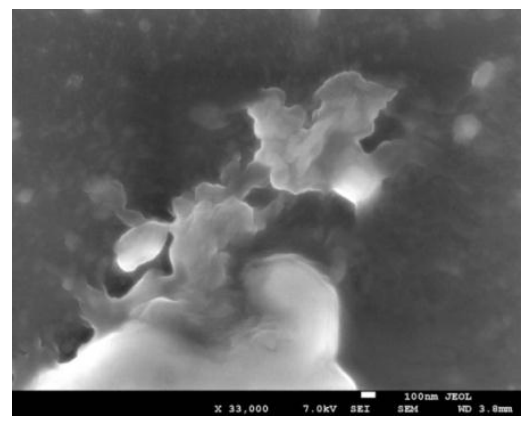

(a) $\mathrm{ZnO} / \mathrm{PVC}$ nanocomposites

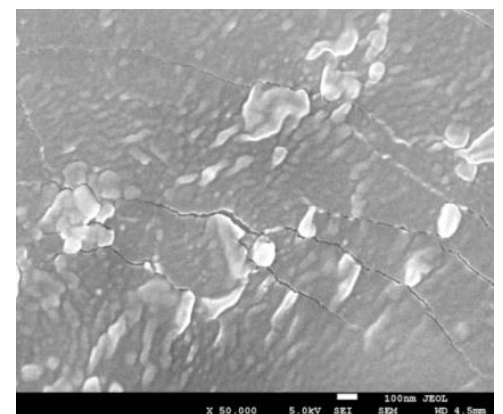

(b) $\mathrm{TiO}_{2} / \mathrm{PVC}$ nanocomposites

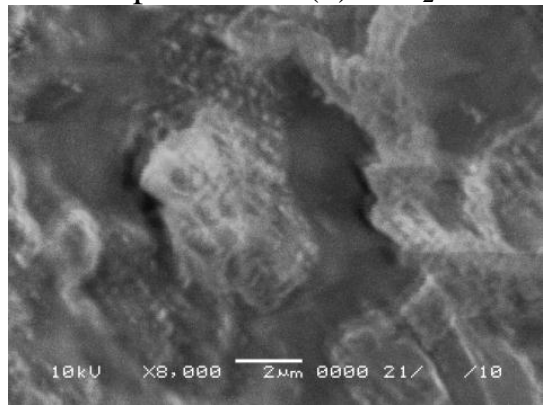

(c) $\mathrm{Al}_{2} \mathrm{O}_{3} / \mathrm{PVC}$ nanocomposites

Figure 2. SEM measurements for PVC nanocomposites

HIOKI 3522-50 LCR Hi-tester device is measuring characterization of nanocomposite insulation industrial materials. Thus, the industrial materials studied here is Polyvinyl Chloride, has been formulated utilizing nanoparticles of $\mathrm{ZnO}, \mathrm{TiO}_{2}$, and $\mathrm{Al}_{2} \mathrm{O}_{3}$. The base of all these polymer materials is a commercially available material already in use in the manufacturing of high-voltage (HV) industrial products and their properties detailed in table 1 . 
TABLE 1

\begin{tabular}{lcc}
\begin{tabular}{c} 
DIELECTRIC PROPERTIES OF PURE AND NANO-COMPOSITE MATERIALS \\
\hline \hline MATERIALS
\end{tabular} & $\begin{array}{c}\text { DIELECTRIC } \\
\text { CONSTANT AT 1 KHZ }\end{array}$ & $\begin{array}{c}\text { RESISTIVITY } \\
(\Omega . \mathrm{M})\end{array}$ \\
\hline Pure PVC & 3.3 & $10^{13}$ \\
$\mathrm{PVC}+1 \% \mathrm{wt} \mathrm{ZnO}$ & 3.24 & $10^{14}$ \\
$\mathrm{PVC}+5 \% \mathrm{wt} \mathrm{ZnO}$ & 3.19 & $10^{14}-10^{15}$ \\
$\mathrm{PVC}+10 \% \mathrm{wt} \mathrm{ZnO}$ & 3.04 & $10^{15}-10^{16}$ \\
$\mathrm{PVC}+1 \% \mathrm{wt} \mathrm{TiO}_{2}$ & 3.94 & $10^{12}$ \\
$\mathrm{PVC}+5 \% \mathrm{wt} \mathrm{TiO}_{2}$ & 4.64 & $10^{12}-10^{11}$ \\
$\mathrm{PVC}+10 \% \mathrm{wt} \mathrm{TiO}_{2}$ & 5.17 & $10^{11}-10^{10}$ \\
$\mathrm{PVC}+1 \% \mathrm{wt} \mathrm{Al}_{2} \mathrm{O}_{3}$ & 3.39 & $10^{13}$ \\
$\mathrm{PVC}+5 \% \mathrm{wt} \mathrm{Al}_{2} \mathrm{O}_{3}$ & 3.59 & $10^{12}-10^{11}$ \\
$\mathrm{PVC}+10 \% \mathrm{wt} \mathrm{Al}_{2} \mathrm{O}_{3}$ & 3.99 & $10^{12}-10^{11}$ \\
\hline \hline
\end{tabular}

\section{Results and Discussion}

PEA system measurements were carried out using two semiconductor cylindrical stainless steel electrodes with diameter $50 \mathrm{~mm}$, and placing specimens in a mineral oil vessel kept at $20{ }^{\circ} \mathrm{C}$. Tests were realized applying an increasing dc breakdown voltage up to $7.5 \mathrm{kV}$. Space charge distribution at various dc voltages stressed and period times can be seen the positive and negative space charge peaks related to the cathode and anode electrodes that found subsequently using variant applied voltages and times. The measurements imply the injection of impulse high voltages on the charge density of Pure PVC dielectric materials; the cathode is at the left and the anode is at the right.

\subsection{Space Charge Accumulation in Pure Polyvinyl Chloride}

Figure 3.a shows space charge distribution in pure polyvinyl chloride under various DC electric fields; the charge density increases with increasing impulse voltages and hetero-charge accumulated near the cathode.

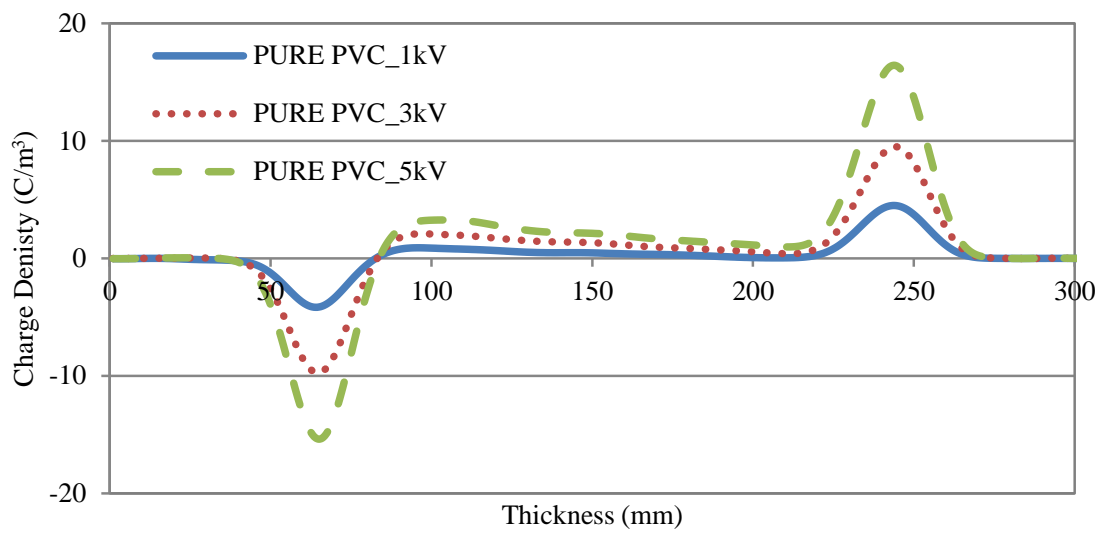

(a) Pure PVC with varying DC voltages

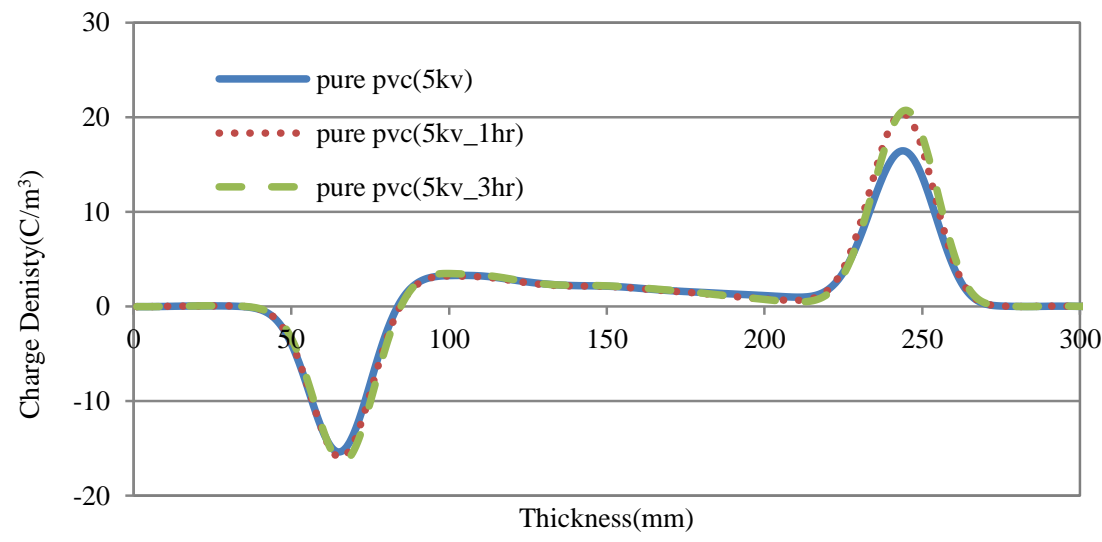

(b) Pure PVC with varying time

Figure 3. Space charge measurement profiles for pure polyvinyl chloride 
On the other wise; Figure 3.b contrasts on the space charge distribution, and its decay happened in remaining $5 \mathrm{kV}$, observed in the samples after three hour space charge electrodes. Charge density increases with remaining impulse voltages at $5 \mathrm{kV}$ especially at the Anode but the hetero-charge accumulated occurs near the cathode. The measurements therefore imply the injection of negative charge from the cathode, which remains trapped close to the injecting electrode when the duration is three hours.

\subsection{Space Charge Accumulation in $\mathrm{ZnO}$ / Polyvinyl Chloride Nanocomposites}

Figure 4.a and Figure 4.b show space charge distributions relevant to $\mathrm{ZnO} / \mathrm{PVC}$ nanocomposite specimens $1 \% \mathrm{wt}$, and $5 \% \mathrm{wt}$ of $\mathrm{ZnO}$ nanoparticles respectively under various DC electric fields. The measurements imply the injection of impulse high voltages on the charge density of $\mathrm{ZnO} / \mathrm{PVC}$ nanocomposites; charging density at the cathode is more than charging density at the anode with increasing $\mathrm{ZnO}$ nanoparticles percentage and impulse applied voltages; especially through 5\%wt specimens and there is hetero-charge accumulated near anode and cathode electrodes. Figure 4.c shows space charge distributions relevant to $\mathrm{ZnO} / \mathrm{PVC}$ nanocomposites with $10 \%$ wt $\mathrm{ZnO}$ nanoparticles percentage under various DC electric fields. The measurements imply the injection of impulse high voltages on the charge density of $\mathrm{ZnO} / \mathrm{PVC}$ nanocomposites; charging density at the cathode is more than charging density at the anode with increasing impulse applied voltages and there is hetero-charge accumulated near the anode. It is noticed that increasing $\mathrm{ZnO}$ nanoparticles from 5\%wt up to $10 \% \mathrm{wt}$ decreasing charge density in the nanocomposite molecules at electrodes. On the other wise, Figure 5 contrasts on the space charge distribution in $\mathrm{ZnO} / \mathrm{PVC}$ nanocomposites with $10 \%$ wt nanoparticles percentage, and its decay that happened in the samples through three hour remaining voltage. Charge density increases with increasing remaining time up to three hours, especially at the Anode.

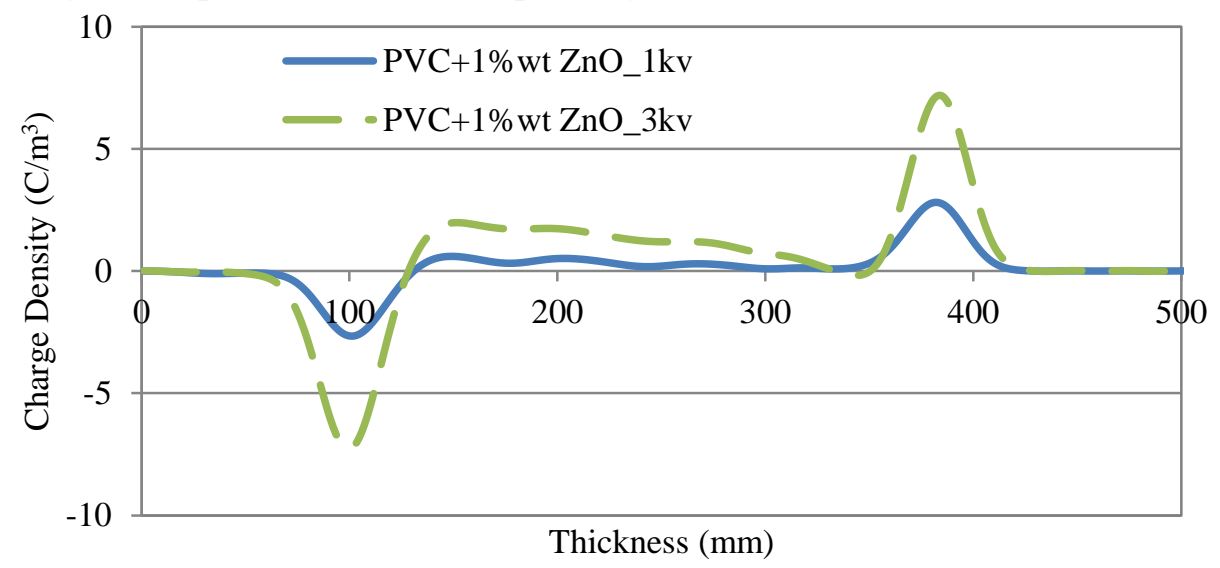

(a) $1 \% \mathrm{wt} \mathrm{ZnO} / \mathrm{PVC}$ nanocomposite

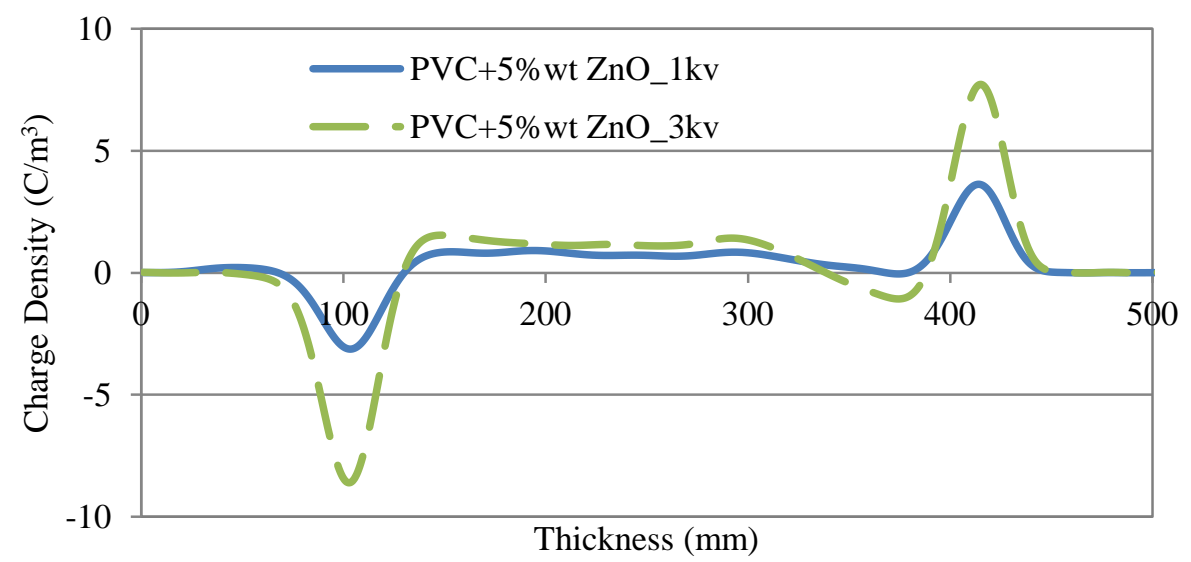

(b) $5 \% \mathrm{wt} \mathrm{ZnO} / \mathrm{PVC}$ nanocomposite 


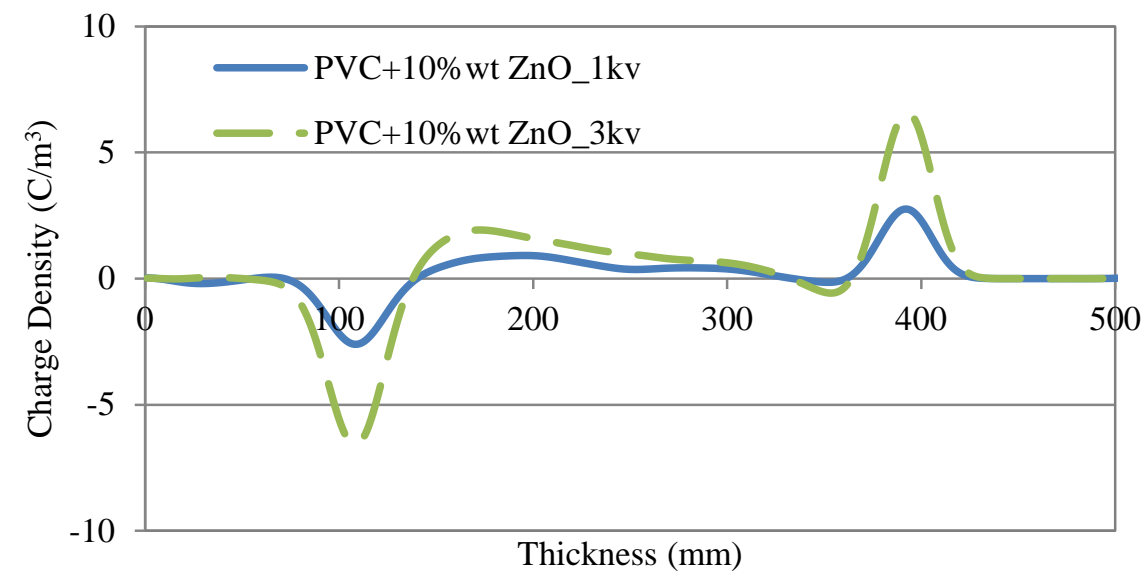

(c) $10 \%$ wt $\mathrm{ZnO} / \mathrm{PVC}$ nanocomposite

Figure 4. Space charge profiles for $\mathrm{ZnO} / \mathrm{PVC}$ nanocomposite with varying $\mathrm{DC}$ electric fields

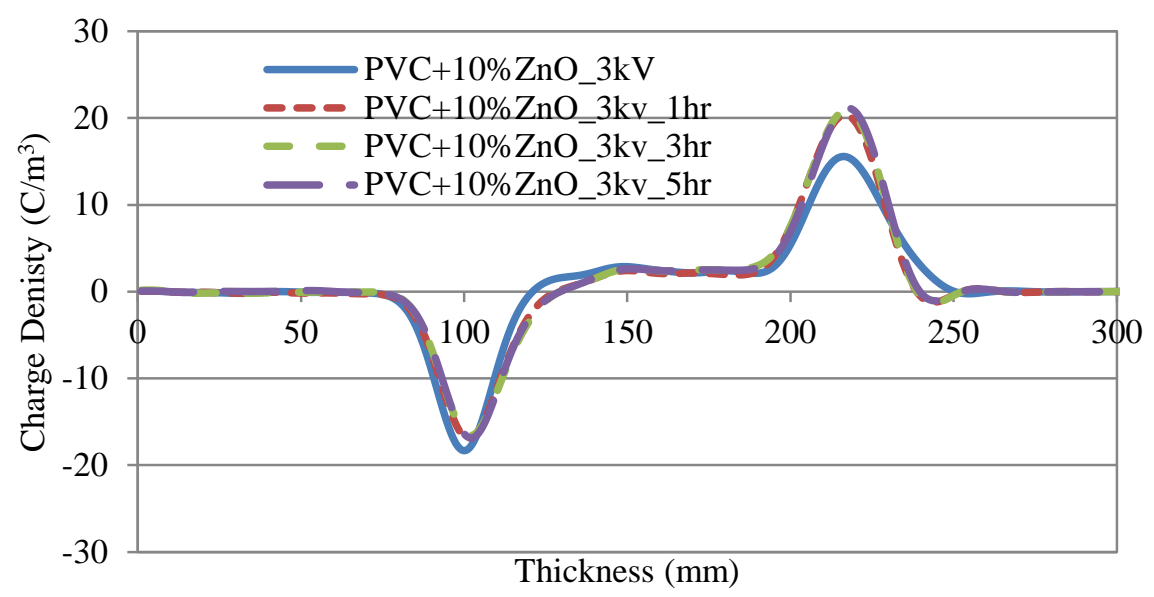

Figure 5. Space charge profiles for $10 \% \mathrm{wt} \mathrm{ZnO} / \mathrm{PVC}$ nanocomposite with varying time

\subsection{Space Charge Accumulation in $\mathrm{TiO}_{2} /$ Polyvinyl Chloride Nanocomposites}

Figure 6.a and Figure 6.b show space charge distributions relevant to $\mathrm{TiO}_{2} / \mathrm{PVC}$ nanocomposite specimens $1 \% \mathrm{wt}$, and $5 \% \mathrm{wt}$ of $\mathrm{TiO}_{2}$ nanoparticles respectively under various DC electric fields. The measurements imply the injection of impulse high voltages on the charge density of $\mathrm{TiO}_{2} / \mathrm{PVC}$ nanocomposites; charging density between electrodes increases with increasing $\mathrm{TiO}_{2}$ nanoparticles percentage and impulse applied voltages; especially through 5\%wt specimens and there is hetero-charge accumulated between electrodes.

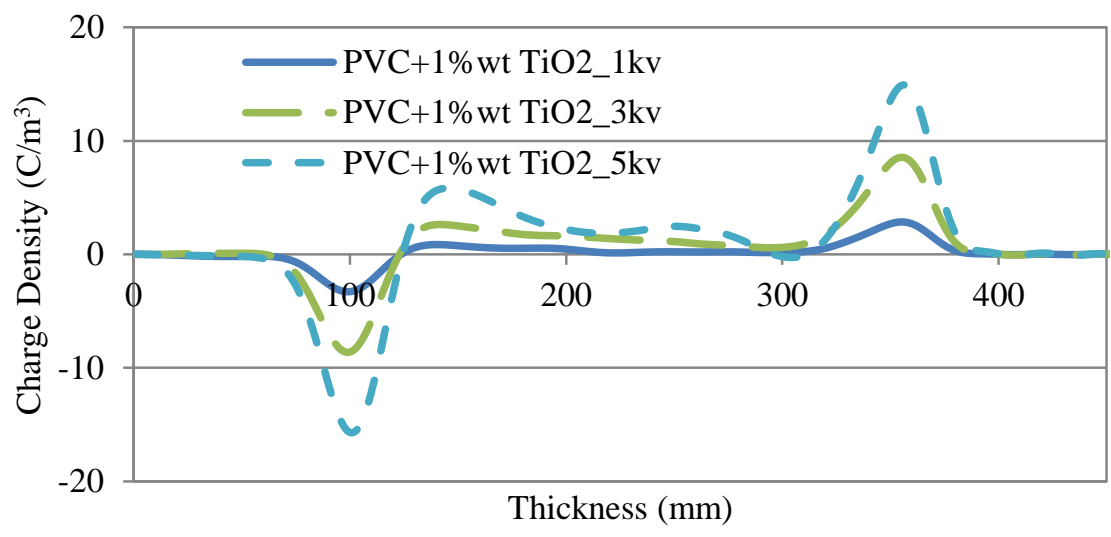

(a) $1 \% \mathrm{wt} \mathrm{TiO}_{2} / \mathrm{PVC}$ nanocomposite 

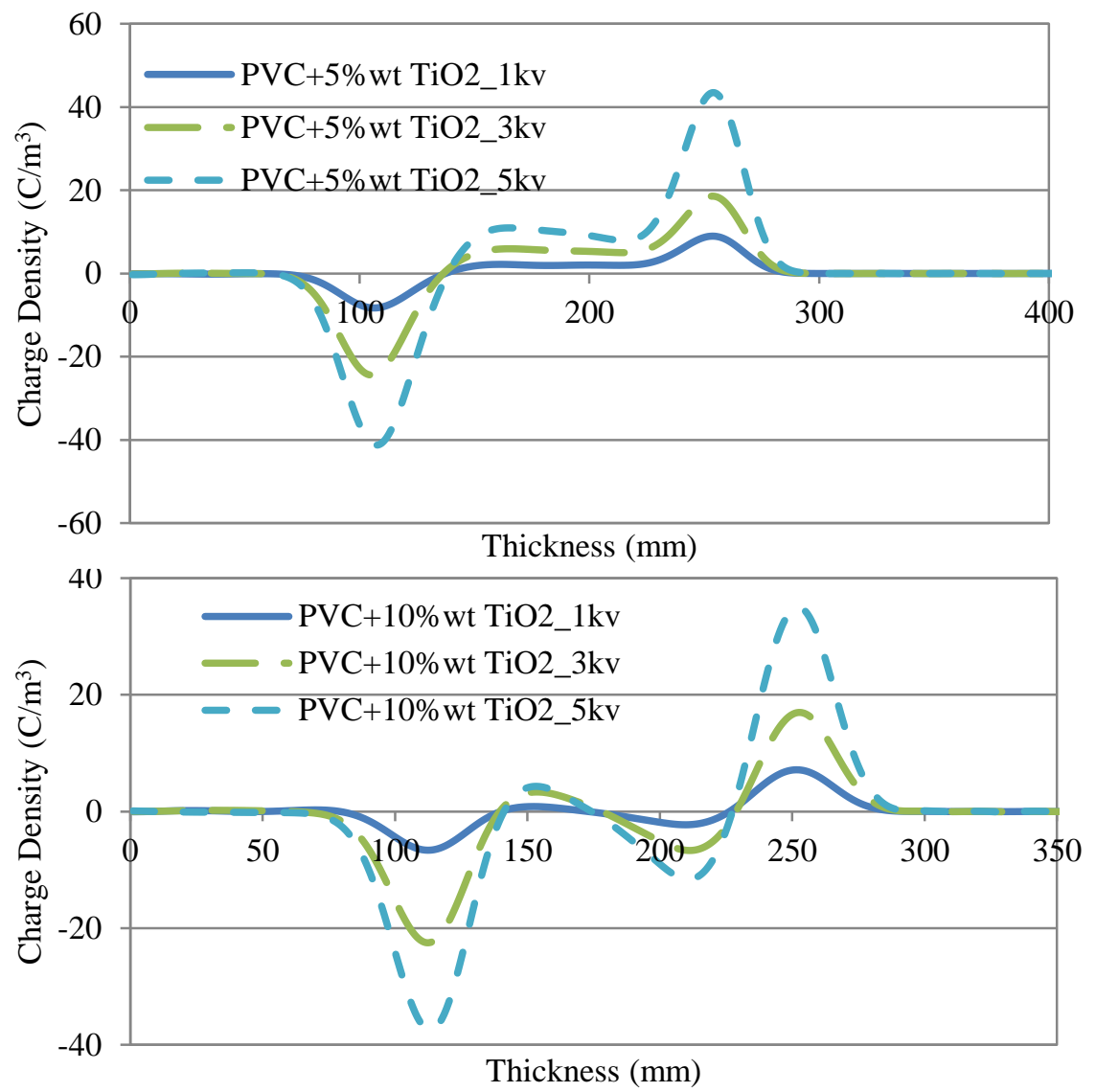

(c) $10 \%$ wt $\mathrm{TiO}_{2} / \mathrm{PVC}$ nanocomposite

Figure 6. Space charge profiles for $\mathrm{TiO}_{2} / \mathrm{PVC}$ nanocomposite with varying DC electric fields

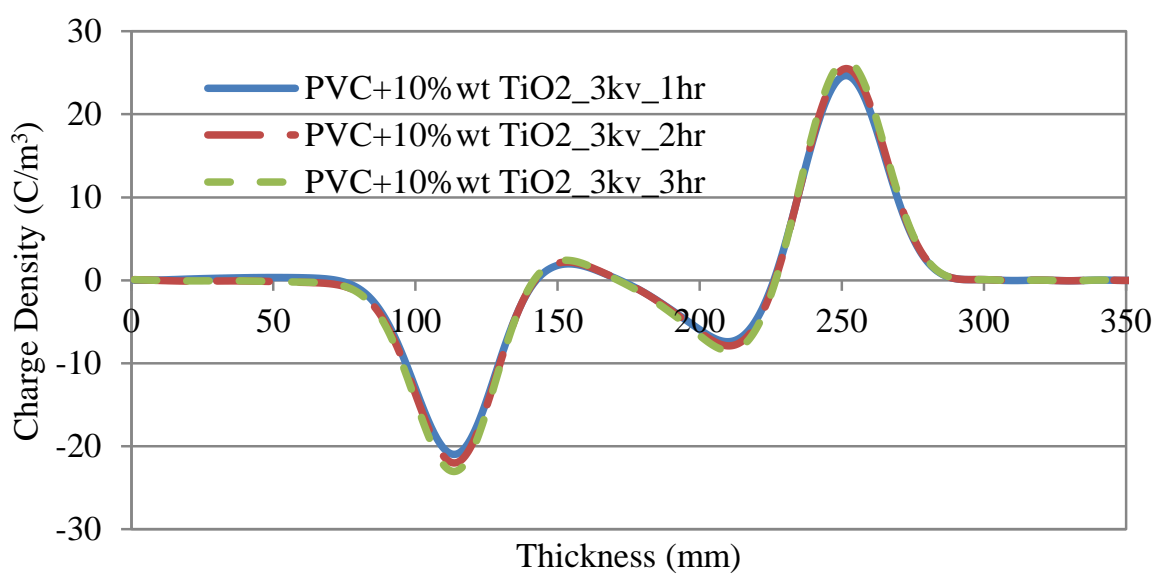

Figure 7. Space charge profiles for $10 \% \mathrm{wt} \mathrm{TiO}_{2} / \mathrm{PVC}$ nanocomposite with varying time

Figure 6.c shows space charge distribution relevant $\mathrm{TiO}_{2} / \mathrm{PVC}$ nanocomposites with $10 \%$ wt nanoparticles percentage with varying DC electric fields. The measurements imply the injection of impulse high voltages on the charge density of relevant $\mathrm{TiO}_{2} / \mathrm{PVC}$ nanocomposites with $10 \% \mathrm{wt}$ nanoparticles percentage; the charge density at both electrodes increases with increasing impulse applied voltages and there is high heterocharge accumulated between anode and cathode electrodes. It is noticed that increasing $\mathrm{TiO}_{2}$ nanoparticles from $5 \%$ wt up to $10 \%$ wt decreasing charge density in the nanocomposite molecules at electrodes. Also, Figure 7 contrasts the space charge distribution with remaining $3 \mathrm{kV}$ over $\mathrm{TiO}_{2} / \mathrm{PVC}$ nanocomposites with $10 \% \mathrm{wt}$ nanoparticles percentage through three hours. There is no changing in Charge density with remaining impulse voltages between both anode and cathode electrodes. 


\subsection{Space Charge Accumulation in $\mathrm{Al}_{2} \mathrm{O}_{3}$ / Polyvinyl Chloride Nanocomposites}

Figure 8 shows space charge distribution relevant $\mathrm{Al}_{2} \mathrm{O}_{3} /$ Polyvinyl Chloride nanocomposites aluminum oxide nanoparticles percentages (1\%wt, 5\%wt and $10 \% \mathrm{wt}$ ) under varying DC electric field $70 \mathrm{kV} / \mathrm{mm}$. The measurements imply the injection of impulse high voltages on the charge density of relevant $\mathrm{Al}_{2} \mathrm{O}_{3}$ /Polyvinyl Chloride nanocomposites with variant nanoparticles percentage; the charge density at both electrodes increases with increasing impulse applied voltages up to $5 \mathrm{kV}$ and there is high hetero-charge accumulated between anode and cathode, specially, in case adding $1 \%$ wt percentage. Noting that, Figure 8.b and Figure 8.c contrast the space charge distribution with remaining $3 \mathrm{kV}$ over $\mathrm{Al}_{2} \mathrm{O}_{3} /$ Polyvinyl Chloride nanocomposites with $10 \%$ wt nanoparticles under varying DC electric field. There is no changing in Charge density with remaining impulse voltages at cathode but there is a very small rising at the Anode.

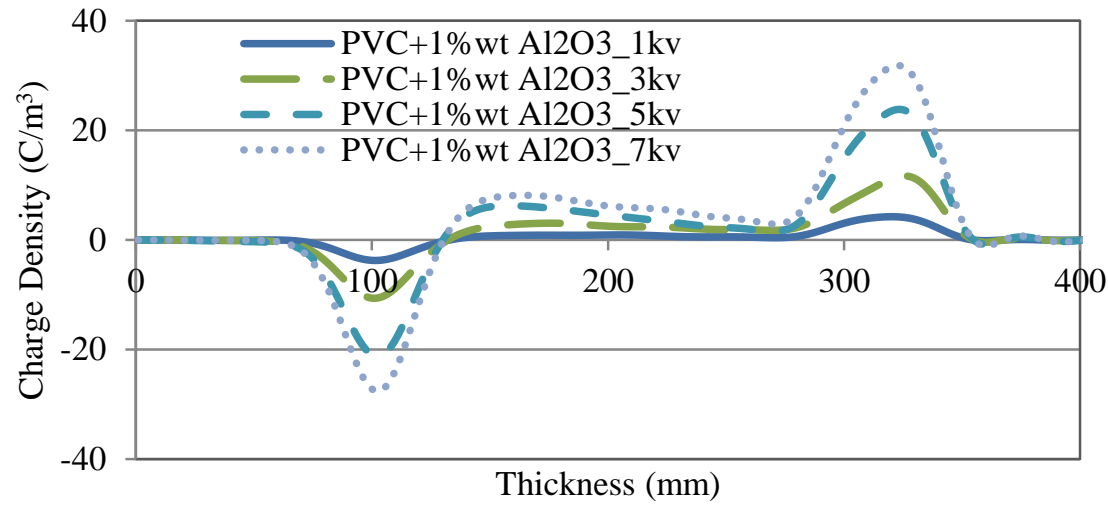

(a) $1 \%$ wt $\mathrm{Al}_{2} \mathrm{O}_{3} / \mathrm{PVC}$ nanocomposite

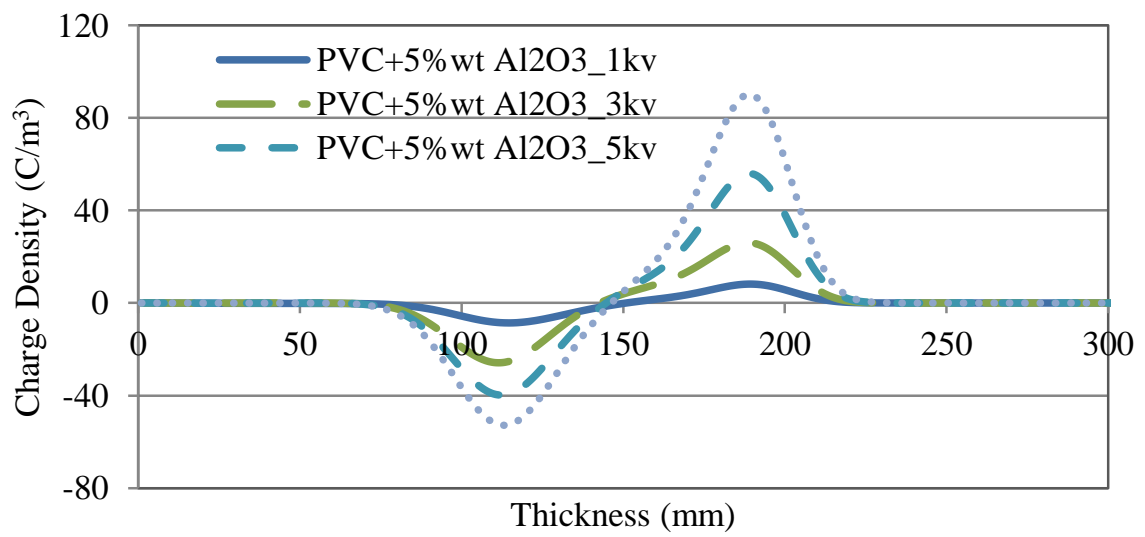

(b) $5 \%$ wt $\mathrm{Al}_{2} \mathrm{O}_{3} / \mathrm{PVC}$ nanocomposite

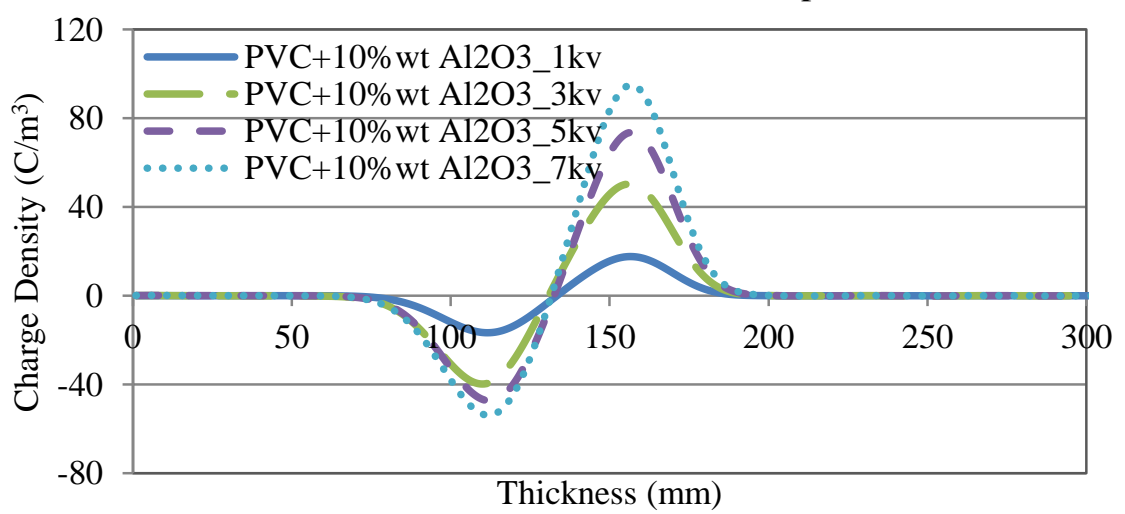

(c) $10 \%$ wt $\mathrm{Al}_{2} \mathrm{O}_{3} / \mathrm{PVC}$ nanocomposite

Figure 8. Space charge profiles for $\mathrm{Al}_{2} \mathrm{O}_{3}$ / PVC nanocomposite with varying DC electric fields 


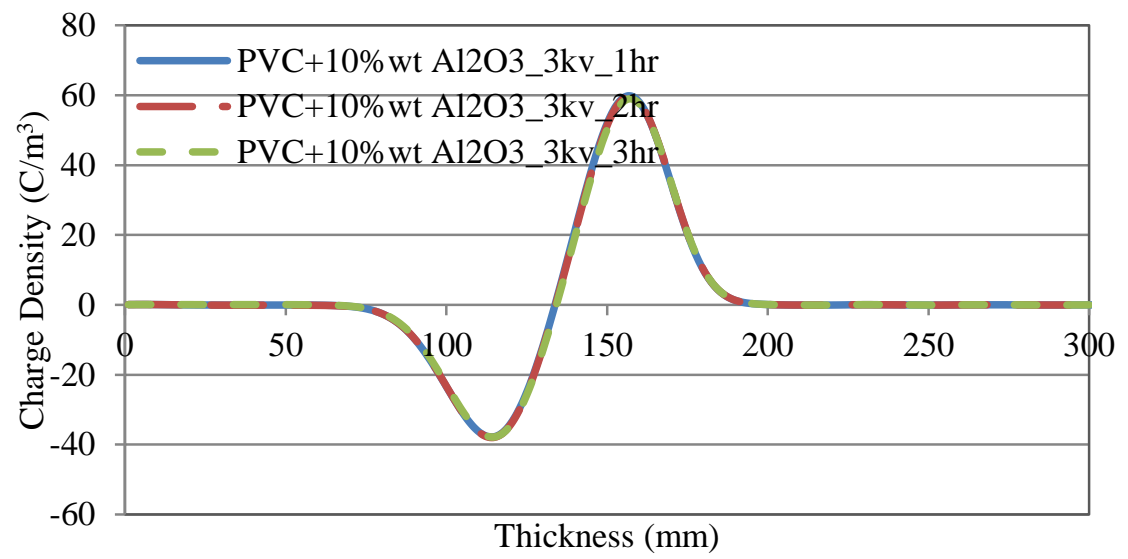

Figure 9. Space charge profiles for $10 \%$ wt $\mathrm{Al}_{2} \mathrm{O}_{3} / \mathrm{PVC}$ nanocomposite under constant DC electric field

Figure 9 shows space charge distribution relevant $\mathrm{Al}_{2} \mathrm{O}_{3} /$ Polyvinyl Chloride nanocomposites with $10 \%$ wt nanoparticles percentage with remaining $3 \mathrm{kV}$ over specimens. The measurements imply the injection of impulse high voltages on the charge density of relevant $\mathrm{Al}_{2} \mathrm{O}_{3}$ /Polyvinyl Chloride nanocomposites with $10 \% \mathrm{wt}$ nanoparticles percentage; there is no increasing in charge density at both electrodes with remaining impulse voltages at cathode and there is no hetero-charge accumulated between anode and cathode

\section{Effects of Nanoparticles on Space Charge of Polyvinyl Chloride}

Space charge accumulation in pure polyvinyl chloride is shown in Figure 3 the charge density increases with increasing impulse voltages and hetero-charge accumulated near the cathode. Also, charge density increases with remaining impulse voltages at the Anode and the hetero-charge accumulated near the cathode. The effect of raising concentration of $\mathrm{ZnO}$ nanofillers in polyvinyl chloride decreases its dielectric constant as shown in table I, whatever, Figure's $(4,5)$ depicts charging density at the cathode is more than charging density at the anode with increasing $\mathrm{ZnO}$ nanoparticles percentage and impulse applied voltages; especially through 5\%wt specimens and there is heterocharge accumulated near the cathode. Increasing $\mathrm{ZnO}$ nanoparticles from 5\%wt up to $10 \%$ wt decreases charge density in the nanocomposite molecules at electrodes. Although, The effect of raising concentration of $\mathrm{TiO}_{2}$ nanofillers in polyvinyl chloride increases its dielectric constant as shown in table I, the charging density at the cathode is more than charging density at the anode with increasing $\mathrm{TiO}_{2}$ nanoparticles percentage and impulse applied voltages; especially through 5\%wt specimens and there is heterocharge accumulated between electrodes as shown in Figure's $(6,7)$. Also, it is noticed that increasing $\mathrm{TiO}_{2}$ nanoparticles from 5\%wt up to $10 \%$ wt decreasing charge density in the nanocomposite molecules at electrodes. On the other wise, Figure's $(8,9)$ show the effect of raising concentration of $\mathrm{Al}_{2} \mathrm{O}_{3}$ nanofillers in polyvinyl chloride increases its dielectric constant as shown in table I, the charging density at the cathode is more than charging density at the anode with increasing $\mathrm{Al}_{2} \mathrm{O}_{3}$ nanoparticles percentage and impulse applied voltages; especially through $1 \%$ wt specimens and there is no heterocharge accumulated between electrodes through 5\%wt and $10 \%$ wt of aluminum oxide. Also, it is noticed that there is no increasing in charge density at both electrodes with remaining impulse voltages at cathode and there is no hetero-charge accumulated between anode and cathode. 


\section{Conclusion}

- Adding $\mathrm{ZnO}$ nanofillers in polyvinyl chloride decreases its dielectric constant but, the charge density at both electrodes increases with increasing $\mathrm{ZnO}$ percentages up to 5\%wt and impulse applied voltages, then; it increases hetero-charge accumulated at cathode. Whatever, adding $\mathrm{TiO}_{2}$ nanofillers in polyvinyl chloride increases its dielectric constant and the charge density at both electrodes increases with increasing $\mathrm{TiO}_{2}$ percentages up to 5\%wt and impulse applied voltages, then; it increases hetero-charge accumulated between electrodes. On the otherwise, adding $\mathrm{Al}_{2} \mathrm{O}_{3}$ nanofillers in polyvinyl chloride increases its dielectric constant and the charging density at the cathode is more than charging density at the anode with increasing $\mathrm{Al}_{2} \mathrm{O}_{3}$ nanoparticles percentage and impulse applied voltages; especially through $1 \%$ wt specimens and there is no hetero-charge accumulated between electrodes through 5\%wt and $10 \%$ wt of aluminum oxide. So, there is no increasing in charge density at both electrodes with remaining impulse voltages at cathode and there is no hetero-charge accumulated between anode and cathode.

- Type and percentage of nanoparticles are vital parameters in specifying electrical aging and the distribution of space charge density accumulation in the nanocomposite molecules between electrodes at DC electric fields.

\section{Acknowedgements}

The present work was supported by the Science and Technology Development Fund (STDF), Egypt, Grant No: Project ID 505. PEA system measurements were done in Electrical and Electronic Engineering Dept., University of Leicester, UK.

\section{References}

[1] G.C. Montanari, "The electrical degradation threshold of polyethylene investigated by space charge and conduction current measurements", IEEE Trans. Dielectr. Electr. Insul., Vol. 7, No. 3, pp. 309-315, 2000.

[2] T. Takada, "Acoustic and Optical Methods for Measuring Electric Charge Distribution in Dielectrics", IEEE Trans. Dielectr. Electr. Insul., Vol. 6, pp. 519-547, 1999.

[3] M. Abou-Dakka, A. Bulinski, S. Bamji, "Space charge development and breakdown in XLPE under dc field”, IEEE Trans. Dielectr. Electr. Insul., Vol. 11, pp. 41-49, 2004.

[4] G. C. Montanari, "Dielectric material properties investigated through space charge measurements", IEEE Trans. Dielectr.Electr. Insul., Vol. 11, pp. 56-64, 2004.

[5] D. Fabiani, G. C. Montanari, L. A. Dissado, Ch. Laurent, and G.Teyssedre, "Fast and Slow Charge Packets in Polymeric Materials under DC Stress" IEEE Transactions on Dielectrics and Electrical Insulation Vol. 16, No. 1; pp. 241-250, February 2009

[6] L. A. Dissado, C. Laurent, G. C. Montanari, and P. H. F. Morshuis, "Demonstrating a Threshold for Trapped Space Charge Accumulation in Solid Dielectrics under dc Field" IEEE Transactions on Dielectrics and Electrical Insulation Vol. 12, No. 3; pp. 612-620, June 2005.

[7] M. Roy, J.K. Nelson, R.K. MacCrone, L.S. Schadler, C.W. Reed, R. Keefe and W. Zenger, "Polymer Nanocomposite Dielectrics - The Role of the Interface" IEEE Transactions on Dielectrics and Electrical Insulation Vol. 12, No. 4; pp.629-643, August 2005.

[8] G. Mazzanti, G.C. Montanari, and L. A. Dissado, "Electrical Aging and Life Models: The Role of Space Charge" IEEE Transactions on Dielectrics and Electrical Insulation Vol. 12, No. 5; pp. 876-890, October 2005.

[9] L. Hu, Y. Zhang and F. Zheng, "Novel Numerical Methods for Measuring Distributions of Space Charge and Electric Field in Solid Dielectrics with Deconvolution Algorithm" IEEE Transactions on Dielectrics and Electrical Insulation Vol. 12, No. 4;pp. 809-814, August 2005. 
[10] T. J. Lewis, "Nanometric dielectrics", IEEE Trans. Dielectr. Electr. Insul., Vol. 1, pp.812$825,1994$.

[11] Cigre Task Force D1.16.03,"Various dielectric characteristics of polymer nanocomposites", Cigre, D1-305, 2006.

[12] M. F. Frechette, M. L. Trudeau, H. D. Alamdari and S. Boily, "Introductory Remarks on Nanodielectrics”, IEEE Trans. Dielectr. Electr. Insul., Vol.11, pp.808-818, 2004.

[13] T. Tanaka, C.G. Montanari and R. Mulhaupt, "Polymer Nanocomposites as Dielectrics and Electrical Insulation-perspectives for Processing Technologies, Material Characterization and Future Applications", IEEE Trans. Dielectr. Electr. Insul., Vol.11, pp.763-782, 2004.

[14] M. Kozako, N. Fuse, Y. Ohki, T. Okamoto and T. Tanaka, "Surface Degradation of Polyamide Nanocomposites Caused by Partial Discharges Using IEC (b) Electrodes", IEEE Trans. Dielectr. Electr. Insul., Vol.11, pp.833-839, 2004.

[15] T. Imai, F. Sawa, T. Nakano, T. Ozaki, T. Shimizu, M. Kozako and T. Tanaka, "Effects of Nano- and Micro-filler Mixture on Electrical Insulation Properties of Epoxy Based Composites”, IEEE Trans. Dielectr. Electr. Insul., Vol.13, pp.319-326, 2006.

[16] M. Kurimoto, H. Okubo, K. Kato, M. Hanai, Y. Hoshina, M. Takei, and N. Hayakawa, "Dielectric Properties of Epoxy/Alumina Nanocomposite Influenced by Control of Micrometric Agglomerates" IEEE Transactions on Dielectrics and Electrical Insulation Vol. 17, No. 3; pp. 662-670, June 2010.

[17] T. J. Lewis, "Interfaces are the Dominant Feature of Dielectrics at the Nanometeric Level”, IEEE Trans. Dielectr. Electr. Insul., Vol. 11, pp. 739-753, 2004.

[18] M. F. Fréchette, M. L. Trudeau, H. D. Alamdari and S. Boily, "Introductory Remarks on Nanodielectrics”, IEEE Trans. Dielectr. Electr. Insul., Vol. 11, pp. 808-818, 2004.

[19] T. Tanaka, G. C. Montanari and R. Mülthaupt, "Polymer Nanocomposites as Dielectrics and Electrical Insulation -Perspectives for Processing Technologies, Material Characterization and Future Applications", IEEE Trans. Dielectr. Electr. Insul., Vol. 11, pp. 763-784, 2004.

[20] T. Tanaka, "Dielectrics Nanocomposites with Insulating Properties", IEEE Trans. Dilectr. Electr. Insul., Vo1. 12, pp. 914 - 928, 2005.

[21] T. Tanaka, M. Kozako, N. Fuse and Y. Ohki, "Proposal of a Multicore Model for Polymer Nanocomposite Dielectrics", IEEE Trans. Dielectr. Electr. Insul., Vol. 12, pp. 669-681, 2005.

[22] B. X. Du, J. W. Zhang and Y. Gao, "Effects of TiO2 Particles on Surface Charge of Epoxy Nanocomposites", IEEE Transactions on Dielectrics and Electrical Insulation Vol. 19, No. 3; June 2012.

[23] Supriyo Das and Nandini Gupta, "Study of Space Charge Characteristics in Epoxy Resin and its Nanocomposites" International Conference on Solid Dielectrics, Potsdam, Germany, pp. 1-4, July 4-9, 2010.

[24] L. Bois, F.Chassagneux, S.Parola, and F.Bessueille. "Growth of ordered silver nanoparticles in silica film mesostructured with a triblock copolymer PEO-PPO-PEO" Journal of Solid State Chemistry Vol. 182, pp. 1700-1707, 2009.

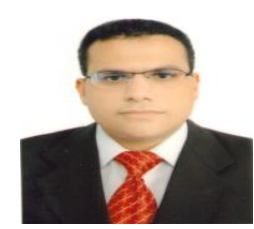

Ahmed Thabet was born in Aswan, Egypt in 1974. He received the BSc (FEE) Electrical
Engineering degree in 1997. He joined with Electrical Power Engineering Group of Faculty of
Energy Engineering in Aswan University as a Demonstrator at July 1999, until; he held Associate
Professor Position at October 2011 up to date. His research interests lie in the areas of analysis and
developing electrical engineering models and applications, investigating novel nano-technology
materials 